Palimpsesto Vol. 10, No 17 (enero-junio, 2020): 1-14

Universidad de Santiago de Chile, ISSN 0718-5898

\title{
Claudio Maíz
}

Universidad Nacional Cuyo

cmaiz@ffyl.uncu.edu.ar

\section{Archivo y canon. Estrategias de visibilidad letrada en América Latina*}

\section{Archive and Canon. Visibility Lettered Strategies in Latin America}

\begin{abstract}
Resumen
Nos ocupamos en este texto de un ensayo-novela del escritor portorriqueño, Eduardo Lalo, titulada Los países invisibles. Para poder realizar una lectura de la pluralidad de sentidos de esta obra, hemos recurrido a un uso metafórico del concepto archivo. A fin de alcanzar ese nivel metafórico ha sido necesario realizar un recorrido por otros modos de concebir el archivo y las diversas funciones que ha tenido en distintos espacios. Nos ocupamos de un conjunto compuesto por el ver, saber y poder que afecta la cultura de países excéntricos. La visibilidad o invisibilidad no es una sencilla cuestión física sino que se involucra de manera intensa con la tríada señalada. Lalo intenta oponer a la creciente invisibilidad de países "menores" un punto de fuga que haga de la excentricidad geográfica una ventaja mediante la configuración de un nuevo lugar de la escritura, esto es, el intersticio que el occidente deja como consecuencia de su ceguera para todo aquello que no le es canónicamente propio.
\end{abstract}

Palabras claves: Archivo, literatura latinoamericana, saber, poder.

\begin{abstract}
In this text we deal with an essay-novel by the Puerto Rican writer, Eduardo Lalo, entitled The Invisible Countries. In order to read the plurality of meanings of this work, we have resorted to a metaphorical use of the archive concept. In order to reach that metaphorical level it has been necessary to take a tour of other ways of conceiving the archive and the various functions that have had in different spaces. We deal with a set consisting of seeing, knowing and power that affects the culture of eccentric countries. Visibility or invisibility is not a simple physical issue that gets intensely involved with the indicated triad. Lalo tries to oppose the increasing invisibility of the "minor" countries a vanishing point that makes geographical eccentricity an advantage by configuring a new place of writing, that is, the interstitium that
\end{abstract}

\footnotetext{
* Este artículo es resultado parcial del proyecto de investigación "Estudio comparativo de prensa gráfica: diarios, revistas y publicaciones político-culturales argentinas de la segunda mitad de Siglo XX a la actualidad", 20182021, subsidiado por la Secretaria de Ciencia y Tecnología de la Universidad Nacional de Córdoba (UNC), Argentina (Res. SECyT 455/18).
} 
the West leaves as a result of its blindness for everything that is not canonically his own.

Keywords: Archive, Latin American literature, knowledge, power.

\section{Introducción}

En el presente trabajo vamos a abordar, en un primer momento, la cuestión del archivo como un instrumento que se enviste de diversas funciones. Tanto el arte como la literatura han aprovechado las potencialidades del archivo para poner en evidencia los cambios de las formaciones históricas. El abordaje del archivo demanda aludir asimismo del canon con el fin de establecer conexiones entre ambos, no porque veamos una relación de oposición ni complementariedad, sino porque mantienen una mutua y necesaria dependencia ${ }^{1}$. En un segundo momento, vamos a ocuparnos con más detenimiento en la dinámica visibilidad/invisibilidad de la materialidad cultural en el texto de Eduardo Lalo, Los países invisibles. ${ }^{2}$ El escritor de Puerto Rico no se ocupa directamente del archivo, sino de la manera como los países metropolitanos actúan como un canon que deja fuera de los campos de visión a "países menores" y sus literaturas consideradas igualmente como "menores". Sin embargo, la obtención de la visibilidad no es una tarea imposible, a condición de que los espacios invisibilizados se tornen en espacios nuevos desde donde escribir.

Si atendemos a Alejandro de Oto, quien ha estudiado las obras de Frantz Fanon y poemas de Aimé Césaire como parte de un archivo colonial, podemos permitirnos entonces un uso metafórico del concepto archivo. Oto ha suspendido la acepción corriente de archivo que se refiere a un "repositorio de materiales que se guardan entre sí una relativa homogeneidad en su forma, configuración y contenido". Lo interesante de su propuesta de análisis es tomar el archivo como "marca fundacional de un modo de reflexión y análisis". Y continúa: "Es decir, pretendemos extender lo que podría llamarse un uso metafórico de la noción de archivo al mismo tiempo que, por su intermedio, intentamos pensar que la constitución del archivo puede alojarse en formatos diversos" (De Oto 2011, p.151). Por su lado, Carmen Perilli ha estudiado las metáforas del archivo en la literatura latinoamericana, y a diferencia de lo que plantea Oto, en cuanto al valor epistemológico que un uso metafórico del archivo puede tener, para ella la literatura misma es una "forma de archivo" y, quizás lo que más relevancia tiene para nosotros, "los archivos en la literatura intentan recuperar la totalidad del archivo cultural". La literatura latinoamericana le concede instancias representacionales tanto de los contenidos como del funcionamiento del archivo" (Perilli, 2013, p.2).

Antes de valernos de ciertos usos metafóricos, reseñemos algunos enfoques sobre el archivo provenientes desde distintas vertientes críticas, de igual valor para los objetivos que nos

\footnotetext{
${ }^{1}$ Del Gizzo concibe la relación en términos de codependencia: "Por lo tanto, canon y archivo establecen una codependencia productiva, siempre disponible para justificar las modificaciones de lo literario en cada presente: mientras el segundo propone una multiplicidad más o menos organizada, pero horizontal y proliferante, el segundo establece recortes y jerarquías." Del Gizzo, Luciana. El Canon frente al archivo. Avatares metodológicos de una relación complementaria. Chuy. Revista de estudios literarios latinoamericanos. Número 5, diciembre 2018, p.50.

${ }^{2}$ Lalo, E. (2014). Los países invisibles. Buenos Aires: Corregidor. A continuación, las páginas de las citas de esta edición se indicarán en el texto.
} 
hemos propuesto. Las perspectivas teóricas del archivo que aprovecharemos no necesariamente forman una cadena metodológica, pero nos permitirán sugerir los recursos y mecanismos que activa un archivo en diversos contextos temporales. Nuestra hipótesis consiste en que situar al archivo en contraposición al canon es un procedimiento mediante el cual es posible visualizar las alteraciones del devenir dialéctico de la cultura. El archivo en tanto repositorio de documentos/testimonios acecha al canon, lo interpela a través de los rastros que indican un pasado, sin mostrar ni hacer aparecer lo que pasó por allí. Mientras que el canon persigue la fijeza, la quietud de lo sabido. Al fin de cuentas, algunas historias de la cultura, señeras en su momento -como la Pedro Henríquez Ureña- estuvieron montadas sobre nombres canónicos, pero a fuerza de desentenderse de la incomodidad del archivo. Canon y archivo son expresiones de la doble faceta de una historiografía. Es necesario explorar, entonces, el archivo a fin de problematizar los abordajes historiográficos de la cultura, desde perspectivas reticulares como un modo de recuperación de voces, objetos, ideas u otros entes que fueron silenciados, soslayados o políticamente ocultados. Se trata de las "materialidades" que han perdido expresión 3 .

\section{Archivo, Estado-nación y escritura}

¿Cuál es el campo conceptual al que pertenece el archivo? El archivo integra un conjunto semántico que está compuesto por la memoria, la historia, el tiempo pasado, estas abstracciones se asocian a su vez con un espacio en razón de que, por lo menos en lo que concierne a los documentos, deben estar reunidos y organizados en un sitio adecuado a tal fin. Aunque el archivo no es un conjunto de documentos preservados por una "sociedad", por caso, libros, revistas, correspondencia, documentos, objetos personales, etc. ${ }^{4}$. En rigor, no es la "sociedad" como un conjunto homogéneo y sin fisuras, intereses o enfrentamientos. Se trata del Estado, en primer lugar, el que realiza, conforme a los intereses que representa, la organización archivística de los documentos calificados como valiosos. En tal sentido, se habla de los archivos institucionalizados que son aquellos que el Estado crea y responde a una política de resguardo en los denominados Archivos Nacionales (Bibliotecas, Repositorios, Universidades, entre otros) y existen los no institucionalizados que permanecen en manos privadas, por lo general con algún vínculo parental respecto de los autores de los papeles resguardados. A decir verdad no son los casos más abundantes pero deben de considerarse. La archivística más destacada entones es la que compete a las instituciones, esto es, a los llamados archivos institucionalizados. Detrás de ellos existe una política archivística, decisiones precisas de lo que se debe resguardar de la destrucción o el paso del tiempo por motivos más ligados al presente que al pasado mismo. Estado-nación y archivo viven en permanente tensión:

El estado-nación (occidental, poscolonial, latinoamericano) -escribe Rufer- tiene una relación paradójica con el archivo. Por un lado, no hay estado sin "sus" archivos que lo

\footnotetext{
${ }^{3}$ Escribe Catanzaro: "[El] problema no es tanto cuál es el tipo de relación con los objetos, con el espacio y los cuerpos, es decir, qué tipo de experiencias materiales propone una determinada imagen, obra o representación del pasado, sino qué materialidades se expresan en ella." (Catanzaro, 2011, p.40) Y agrega: "[...] a un texto literario, este materialismo no preguntará por la manera en que se trama allí una determinada experiencia de clase, sino por la experiencia que se manifiesta en él [...]" (Catanzaro, 2011, p.40).

${ }^{4}$ Esta es la visión que sostiene Del Gizzo en su estudio. Nuestra perspectiva apunta a complejizar el campo mediante la incorporación de mayores elementos (De Gizzo, 2018).
} 
legitimen y le den plena existencia en el continuo temporal. Por otro, el archivo es una amenaza latente para el estado. El propio registro de pugnas, voces diversas y subversiones a la legitimidad y al orden se vuelven una amenaza al sentido mismo de su legitimidad. (Rufer, 2016, p.166)

El archivo como legitimación, pero también como amenaza. Hace unos años Rodrigo Rey Rosa escribió El material humano (2009) una novela autoficcional que trabaja con los fondos de los archivos históricos de la Policía Nacional de Guatemala. Lo destacable de ello es que tales fondos fueron el resultado de un descubrimiento casi fortuito y no de una relectura o de alguna otra operación desestabilizante del archivo. En 2005, mientras se desmantelaban explosivos en un edificio, se hallaron los documentos de la antigua Policía Nacional comprendidos entre 1882 a 1997. El contenido de este archivo facilitó la resolución de graves delitos cometidos por agentes estatales:

Por mi parte, más allá de la información -escribe Rey Rosa en la "Introducción"- que esperaba obtener en ese laberinto de millones de legajos policíacos acumulados durante más de un siglo y conservados por azar, después de aquella visita inicial las circunstancias y el ambiente del Archivo de La Isla habían comenzado a parecerme novelescos, y acaso aun novelables. Una especie de microcaos cuya relación podría servir de coda para la singular danza macabra de nuestro último siglo. (Rey Rosa, 2009, p.13) ${ }^{5}$

En América Latina es muy interesante observar el papel cumplido por el archivo desde los tiempos precolombinos, pasando por la etapa colonial y durante la emergencia de las repúblicas. Con la llegada del imperio español se cierra la etapa del desorden que reinaba en un mundo sin escritura. Según Ángel Rama el orden demandaba un script que diera fe de la realidad mediante la escritura. Fue el inicio de la carrera imperial en el continente a través del fetichismo escritural (Rama, 2004, p.43). De tal modo, la palabra escrita "viviría en América Latina como la única valedera, en oposición a la palara hablada que pertenecía al reino de lo inseguro y lo precario" (Rama, 2004, p.43). Esta operación evaporó el pasado, concluye el crítico uruguayo (Rama, 2004, p.46). La oralidad pertenece al campo de la memoria y el rescate de esta tradición no escrita o escrita por los informantes españoles es una tarea que compromete especialmente a los etnógrafos. Se podría pensar entonces en dos registros archivísticos, para esta etapa uno que tiene que ver con la escritura y otro con la oralidad y la memoria. Una distinción en el sistema ideado por Rama que permitió el desarrollo fructífero de la noción de transculturación narrativa, por cuanto las novelas más logradas de la narrativa del siglo XX lo fueron gracias al procedimiento que implicaba la recuperación de las sociedades arcaicas, eminentemente orales (como han sido los casos de Rulfo, Arguedas, Guimarães, Roa Bastos). Desde el punto de vista historiográfico, la memoria oral está inmersa en el mundo del mito o la épica, de ahí que carezca de valor para la organización de los sucesos del pasado. El peso del documento se impone como la única validación autorizada de la historia. La literatura, en cambio, no le da prioridad a las temporalidades que conviven en América Latina. Mantiene abierto el conflicto entre la

${ }^{5}$ Véanse para el tema: Coto-Rivel, S. (2015); Albizúrez Gil, M. (2013) 
temporalidad cíclica del mundo indígena y la lineal de los europeos (Ocampo López, 2006, p.402) ${ }^{6}$.

La documentación conservada fue la producida por la cultura europea mediante el ejercicio burocrático y como factor de poder que encerraba la escritura alfabética. El primer archivo de una región colonial, como era de esperarse, se estableció en una ciudad metropolitana como Sevilla en 1785, con el nombre de Archivo General de Indias. Con el proceso de las independencias se abrirá un vertiginoso propósito de recuperar los materiales escritos como fuente de autodeterminación de los territorios que iban siendo liberados y que a la postre impactarían en la creación de los Estados nacionales. El control de esas fuentes tornó el asunto en un tema de interés político y así surgirán los primeros repositorios convertidos en archivos nacionales. El trayecto comenzó en los años 1820 hasta finales del siglo XIX.

En la literatura latinoamericana el archivo ha ocupado un lugar preponderante, a punto tal que Roberto Gonzáles Echavarría junto con el mito y el archivo dio cuerpo a una teoría de la literatura latinoamericana (González Echavarría, 2000). Se debe de recordar la novela de Carlos Fuentes, Gringo viejo (1985) en la que una de las temáticas que atiende la novela compete justamente a la posesión de los documentos que acrediten una propiedad ancestral de las tierras que la revolución mexicana pretende recuperar. El gringo viejo, como espectador de esta disputa de papeles, reflexiona amargamente: "papeles al cabo, pero qué diferente manera de saberlos, ignorarlos, guardarlos: este archivo del desierto va corriendo y no sé a dónde va a ir dar, no lo sé, [...]" (Fuentes, 1985, p.35). El general Arroyo un hijo no reconocido por el propietario de la hacienda es el que está convencido de los efectos legales que tendrán los documentos. "La historia de los papeles era la historia de Arroyo"; "el mexicano acarició los papeles como acariciaría la mejilla de una madre o la cintura de una amante" -nos ilustra el narrador- (Fuentes, 1985, p.35).

\section{Archivo, saber y poder}

El archivo se reserva no solo la función defensora, sino la de ser fuente de poder, con más énfasis a partir de los siglos XVII y XVIII con el nacimiento del Estado moderno. La archivística se torna "doctrina jurídica al servicio de la nueva administración" (Pieró, 2001, p.250). De tal manera que el archivo ocupa un lugar central en la maquinaria burocrática y administrativa del nuevo Estado, adquiriendo, por ello, una función predominantemente jurídico-política. El documento devenía en garante de la legitimidad del poder. Sería la época de los "archivos como arsenal de la autoridad", como la había llamado el francés Bautier (Pieró, 2001, p.250). En su conocida novela El Archivo de Egipto, Leonardo Sciacia desenmascara la impostura del archivo puesto al servicio de la preservación de los bienes patrimoniales de la estructura feudal de Sicilia. Ambientada hacia finales del siglo XVIII, la novela tiene como uno de los personajes centrales a un capellán maltés, Giuseppe Vella, quien crea dos falsos manuscritos históricos: el archivo de Sicilia, y el archivo de Egipto. Vella más allá de sus ambiciones de fama y poder, paulatinamente va comprendiendo el significado de los archivos para una nobleza que basa su autoridad en los documentos. En consonancia con el virrey Caracciolo, un reformista, que se había propuesto destruir toda la doctrina jurídica feudal, Vella advierte la existencia de un complejo de doctrinas sicilianas que como un "arsenal de autoridad" estaba al servicio de los privilegios de los barones.

${ }^{6}$ Véase también para la problemática del tiempo en América Latina: Salinas C., M. (2019). 
Ese cuerpo - agrega el narrador- jurídico constituía una yuxtaposición de elementos históricos aislados con sabiduría, definidos e interpretados luego. Y esa legislación se había mantenido en un puesto inexpugnable, hasta aquel momento. Sólo hasta aquel momento, porque el virrey reformador y el soberano ávido comenzaban a advertir la impostura del macizo cuerpo jurídico. (Sciascia, 1985, p.42)

La hermenéutica cumple una función axial, puesto que mediante ella se le asigna orden y sentido al archivo. Un cuerpo jurídico que ordenado e interpretado insidiosamente, hacía de esos documentos el soporte central de una impostura jurídico-política en la que se asentaba el poder patrimonial de la nobleza. La impostura del falsario Vella es también parte de la gran impostura que vive Sicilia. El engaño de los archivos inventados por Vella no iba en saga a los engaños de los archivos interpretados por la nobleza. Robert Bautier había establecido distintas divisiones cronológicas del archivo: la Edad Antigua, con la que se corresponden los Archivos de Palacio; la Edad Media, periodo caracterizado por los denominados Chartiers o Trésors de Chartes (Tesoros de documentos o Tesoros documentales); la Edad Moderna, que veía nacer los Archivos de Estados, donde el autor definía la principal función de los archivos como "arsenal de autoridad"; finalmente, la Edad Contemporánea, cuando los archivos pasaron a convertirse en los laboratorios de la ciencia histórica. (Montes, 2008)

Esta dimensión del archivo que lo asocia al poder y la legitimación de un determinado régimen o grupo social nos parece digno de observarlo con mayor detenimiento, en razón de que el canon - un orden establecido e impuesto por una fuerza específica- estaba en cierto modo contenido en el archivo como parte de una política de lo autorizado. El impulso canonizador toma su potencia del mismo archivo, que ya ha sido organizado de acuerdo con alguna orientación política, como se dijo. Por lo dicho, no habría canon sin archivo o para no ser tan taxativos, se establecen ciertas canonizaciones de acuerdo con ciertas políticas del archivo.

¿Cómo desautorizar al canon sin recurrir al archivo convencional? Lo dicho hasta aquí ha incursionado mayormente en la faceta material, tangible o simbólica del archivo pero no termina de definirlo en toda su dimensión. Hay otra manera de comprenderlo a contracorriente de como usualmente se lo describe. Foucault condujo la descripción del archivo al campo de las prácticas discursivas y no de la historia. Esas prácticas constituyen "sistemas que instauran los enunciados como acontecimientos (con sus condiciones y su dominio de aparición) y cosas (comportando su posibilidad y su campo de utilización). Son todos esos sistemas de enunciados (acontecimientos por una parte, y cosas por otra) los que propongo llamar archivo" (Foucault, 1985, p.219). El archivo es capaz de alcanzar otras funciones si su contenido no es tomado como una mera catalogación documental del pasado o un mecanismo que active ciertas memorias. En razón de esta doble perspectiva, el archivo se hace un dispositivo manipulable, de una intensa inestabilidad política. El archivo posee alcances sobre la visibilidad o la invisibilidad de las cosas. A veces con mucha astucia no necesita recurrir al ocultamiento, razón por la cual la visibilidad de lo ausente no es un problema de búsqueda de nuevos "documentos" sino de revisión de los que se tienen a la vista. El poder del estado emite directivas precisas y codificaciones que responden a los parámetros del orden que impuso la modernidad, que priorizó la catalogación y la división de saberes. Foucault no veía en el archivo "la suma de todos los textos que una cultura ha guardado en su poder como documentos de su propio pasado, o como testimonio de su identidad mantenida" ni entendía por archivo "las instituciones que, en una sociedad determinada, permiten 
registrar y conservar los discursos cuya memoria se quiere guardar y cuya libre disposición se quiere mantener" (Foucault, 1985, p.219).

Para Foucault el archivo es un acontecimiento del discurso. En la lectura que hace Giorgio Agamben de esta mirada foucaultiana del archivo, se observa que este se sitúa entre la langue en tanto sistema de construcción de frases posibles (la posibilidad de decir) y "el corpus de lo ya dicho, de las palabras que han sido efectivamente pronunciadas o escritas." Y agrega: "[El] archivo es, pues, la masa de lo no semántico inscrita en cada discurso significante como función de su enunciación, el margen oscuro que circunda y delimita cada toma concreta de palabra" (Agamben, 2016, p.150). Esta dimensión discursiva del archivo, alerta sobre los usos de la huella en relación con la ausencia, de lo que no está pero puede reponerse gracias a la marca dejada. Es un punto neurálgico para la historiografía que no ha reflexionado sobre todas las implicancias que ello conlleva. El trazo, la marca reposa sobre una metafísica de la presencia que se activa mediante una operación metonímica, cuando repone el todo (lo ausente) a partir de una parte ${ }^{7}$.

Desde esta perspectiva se nos hace más factible extremar los vínculos entre archivo y canon. A la postre canon y archivo constituyen regímenes de lo que está autorizado decir como de aquello que brega por decirse. Ambos pertenecen "al sistema de la discursividad" (Foucault, 1985 , p.219) es decir a "las posibilidades o imposibilidades enunciativas que éste dispone" (Foucault, 1985, p.219) Nuevamente en palabras de Agamben: "Entre la memoria obsesiva de la tradición, que conoce sólo lo ya dicho, y la excesiva desenvoltura del olvido, que se entrega en exclusiva a lo nunca dicho, el archivo es lo no dicho o lo decible que está inscrito en todo lo dicho por el simple hecho de haber sido enunciado, el fragmento de memoria que queda olvidado en cada momento en el acto de decir yo." (Agamben, 2016, p.150) El canon es la memoria obsesiva de la tradición, lo que ha sido dicho y moldeado al tiempo que le compete, el archivo, aunque es lo que no ha sido dicho aún, se encuentra incrustado en todo aquello que se ha dicho.

\section{El archivo de Occidente}

Una posibilidad complementaria de las anteriores es la de confrontar a niveles más amplios los desempeños cumplidos por el archivo hegemónico europeo-occidental. Los estudios poscoloniales han propuesto la composición de una historia de la cultura sur/sur y relativizar de tal modo el archivo europeo. Ortiz Wallner ha estudiado las construcciones orientalistas de herencia decimonónica que recorren la literatura latinoamericana. $\mathrm{Su}$ enfoque procede precisamente de la crítica poscolonial más reciente, en cuanto al "dominio de la matriz dialéctica transatlántica de circulación de saberes, cuya lógica lineal de ida y vuelta entre Europa y América, es decir, entre metrópolis y antiguas colonias, ha desplazado y pospuesto largamente la mirada y el estudio sobre otras formas de circulación de ideas y de saberes, por ejemplo, aquellas entre las llamadas periferias del Sur global" (Ortiz Wallner, 2018, p.100). El archivo de

\footnotetext{
${ }^{7}$ Seguimos a Rufer en este punto: "Aquí hay dos operaciones sobre las que vale la pena reflexionar: primero, la historia hereda aquí la impronta de una encrucijada sémica generalmente pasada por alto. La huella, por definición, es un signo indéxico. Sólo puede pensarse en relación con la ausencia, con aquello que dejó una marca pero ya no está presente más que como trazo. Ése es un punto neurálgico porque la noción de huella ha sido pensada en la disciplina como "prueba de la presencia" que permite "rehacer el original". De tal modo que una relación indéxica, de segundidad, aquello que sabemos que existió por la marca dejada, pasa a ser metonímica: pretende constituirse en la parte que permite reconstruir el todo; [...]" (Rufer, 2016, p.163).
} 
Occidente durante siglos ha creado trayectos de circulación unidireccionales, con un impactante desconociendo de otros trayectos posibles y que han comenzado a generarse desde los márgenes.

Si como ha escrito Foucault el archivo "es en primer lugar la ley de lo que puede ser dicho, el sistema que rige la aparición de los enunciados como acontecimientos singulares" (Foucault, 1985, p.219) es probable que el arte sea capaz de valerse del archivo para llevar a cabo operaciones depuradoras, transgresoras o restituyentes en tanto "acontecimientos singulares". Con todo, visto de una manera institucionalizada, el archivo padece de los males del museo, por cuanto la cosificación del arte en un espacio cerrado y sometido a determinadas reglas desmantela el poder transgresor que pudiera haber poseído. El papel jugado por las vanguardias internacionales en la transformación perceptiva son un buen ejemplo.

En la noción de archivo, lo temporal es imprescindible para el análisis. El uso del archivo tanto por los contemporáneos como de los sucesores puede ser examinado como herramienta que permite la ligación de la historia como realidad con la historia en nivel de discurso. Los archivos y documentos/testimonios, a través de los rastros, indican el paso del pasado, la anterioridad del rasguño, sin mostrar, sin hacer aparecer lo que pasó por allí (Ricoeur, 2006, p.905). La idea de sucesión de generación o del reino de los predecesores, de los contemporáneos y de los sucesores solamente adquiere sentido de coparticipación, de comprensión y de comunicación recíprocos entre sus miembros si se incluyen las nociones de rastro, de documento, de monumento, de archivo, museos, bibliotecas, es decir, acervos (Ricouer, 2006, p.905). Así como también las perturbaciones individuales de la memoria nos acercan estados que van más allá de lo psicológico y pueden razonarse en términos culturales. Nos referimos a los trastornos de la memoria como la hipomnesia, una disminución de la capacidad de retener o evocar recuerdos, la amnesia, la incapacidad para recordar eventos durante un período de tiempo y la hipertimesia, el aumento de la función de evocación. Males que pueden estar contenidos en el binomio archivo-canon.

\section{Archivo y la visibilidad}

Occidente entendido como una construcción canonizada oculta países y ciudades. El gran archivo que constituye, asentado sobre el poder y el tiempo es una máquina jerarquizadora que establece lo que es apreciable y lo que no. En buena parte esta es la visión de Eduardo Lalo, el escritor de Puerto Rico, desplegada en el ensayo-novela Los países invisibles (2014). La referencia a Las ciudades invisibles (1972) de Italo Calvino parece obligada, aunque Lalo no haga mención a esta obra. Aun así, las ciudades invisibles del escritor italiano surgen del relato de Marco Polo al rey de los tártaros Kublai Kan. Son ciudades del lenguaje y no de la geografía, única manera que tiene el emperador de formarse una idea del imperio que ha construido ante la imposibilidad de conocer a todas las ciudades. Ello no le impide darse cuenta de que el centro de su imperio no es un significado sino un significante vacío o la invisibilidad es una condición constitutiva de ellas. Y en este punto es donde Calvino y Lalo se rozan. Somos conscientes de que establecer una relación entre ciudad (o por extensión, un país) y el archivo es problemático y a su vez, desde ahí, extender lazos hacia la visualidad. Estamos ante una triple perspectiva consistente en ver, saber y poder. Los países invisibles de los que habla Eduardo Lalo son "víctimas" del archivo visual, esto es, los países invisibles carecen de consideración en virtud de que no se encuentran en el campo de visión digno de tomarse en cuenta y por tanto preservarse en tanto imagen. Aunque este dilema de la visibilidad o la invisibilidad bien podrían estar en la línea 
teórica foucaultiana, la invisibilidad ya no solamente de los países sino en especial de sus culturas. Se ha producido una licuación de las diferencias en el contexto de un sistema global. Probablemente, estamos a las puertas de una nueva formación histórica. Para entender mejor esta noción de Foucault, en la paráfrasis de Gilles Deleuze una nueva formación histórica es el "agenciamiento de lo visible y de lo enunciable", "una manera de combinar visibilidades y enunciados" (Deleuze, 2013, p.33). Pero resulta imposible especular el tema así, por lo menos desde la perspectiva que nos ofrece Eduardo Lalo, para quien hay una disrupción entre visibilidad y enunciación. Eso no impide que en algún momento "el régimen de enunciados" y el "campo de visibilidades" varíen y se constituya una nueva formación histórica. Por ahora Lalo se limita a constatar la disrupción y no la convergencia. Para contrarrestar los efectos de la invisibilidad, entonces, se debe exhumar aquello que está presente pero invisible en la cultura no globalizada. En la obra de Lalo hay un tránsito de archivo de la ciudad a la ciudad como archivo. Lalo no se ocupa especialmente de los archivos, sin embargo, tomar el archivo como un medio permite una lectura en la que se pueden "recorrer espacios vacíos del presente" (Rao, 2008, p.204). Se trata de un uso metafórico del concepto archivo como un recurso para comprender algunos escenarios cambiantes de la cultura contemporánea. La ciudad como archivo sería un modo de "introducir el pasado dentro del presente como un fenómeno temporal ausente", inconcluso, en el que "la ciudad sea un palimpsesto de formas históricas y que no concibe al archivo como un mero depósito de dichas formas" (Rao, 2008, p.205).

No es una búsqueda de capas sedimentas lo que está en juego y que podrían hallarse a nivel de la superficie plana de las materialidades culturales; no es tampoco una arqueología de las profundidades sino de lo que está pero no es visible. No es en la profundidad entonces donde la búsqueda debe realizarse sino en la extensión donde la tarea cobra mayor sentido. Si el "inconsciente se estructura como un lenguaje, y todo lenguaje es, en sí, evidencia, sólo que dicho evidenciarse se difumina en la impersonal red de desplazamientos y diferencias de los signos" (Hernández Navarro, 2009, p.33). ¿Qué es entonces lo visible? No es precisamente aquello que todos alcanzan a ver porque sería irrelevante decirle a otro lo que está viendo. En la interpretación que Deleuze hace sobre la visibilidad en la obra de Foucault establece una disyunción entre hablar y ver. "Lo que se ve -escribe Deleuze- no reside en lo que se dice. Lo que se dice no hace ver" (Deleuze, 2013, p.31). Trasladado al plano de las funciones del archivo, no es el vacío de lo que no se dice lo que oculta a la mirada las materialidades de los fenómenos culturales, sino lo que se ve pero deliberamente no se dice. Existe un lenguaje autorizado que también rige en los archivos e incide en sus potencialidades. "No se puede ver -escribe Lalo- lo que la ley no ha nombrado". Si el discurso mundialista no nombra, sobreviene la invisibilidad. Continúa Lalo:

Pero detrás de estas ausencias quedan multitudes, pueblos enteros que no tienen palabras ni conceptos oficializados, visibles, para representarse, para reiterar ante otros su existencia. Estos son los países invisibles y su invisibilidad no es transparente, sino que al contrario, constituye una forma de opacidad y entre ellos y los visibles, que les "ven" en un acto que consiste en no-ver, en borrar o liquidar, no hay una fina veladura sino una densa membrana plástica. Los países invisibles son pues una forma de antirepresentación. Esta es la señal de identidad de las sociedades que no han accedido a la visibilidad de los discursos establecidos. Pero la premisa que da "existencia" a los países invisibles se centra en que estos discursos no son los únicos. En otras palabras, que invisibilidad es también un discurso. (p.172) 
Se ha perdido la capacidad de admitir de que detrás de lo que queda en la oscuridad comporta un espacio otro habitado por multitudes. Si el mundo no es el mismo es porque ya no es diferente, razona el escritor isleño al comienzo de su libro. El primer lugar, declara como invisible a la propia isla donde vive, Puerto Rico. Pero el mal de la invisibilización es creciente y no afecta solo a los contornos del mundo globalizado, sino también a ciudades de países pertenecientes al campo privilegiado de la visibilidad (Madrid, Venecia entre otros) ${ }^{8}$. Sin embargo, mediante la escritura es posible resistir a la uniformidad. Dice Lalo: "La verdadera oposición [es] el acto activo de la escritura a la pasividad del que recorre la tradición leyéndola. Escribir es alterar. /.../La creación aparece cuando se ha llegado al límite de lo es posible decir, cuando literalmente se ha salido de este límite con lo escrito" (128). En lugar de centrarnos en la capacidad del archivo para representar un pasado, se podría utilizar el concepto de archivo para recorrer aquellos espacios vacíos o invisibles del presente (Rao, 2008, p.204). La escritura, o si se quiere los enunciados, resulta el único acto de resistencia crítica que resta. Si todo permanece en invisibilizado es en razón de que no han salido a la luz. "Las visibilidades - razona Deleuze- no son solamente datos como los otros, son condiciones de luz que vuelven posible el tránsito, el ascenso a la luz del día de lo que se hace y se padece en una época" (Deleuze, 2013, p.27). La ciudad o el país vistos como un archivo en el sentido foucaultiano, logran superar el límite de lo decible. Cuando ello ocurre se ha avanzado un paso hacia la visibilización.

Escribir desde la invisibilidad -dice Lalo- significa ampliar el campo miope de lo visible. Así puede sacarse, aunque sea mínimamente, a las tradiciones hegemónicas, a las literaturas narcisistas, a los centros literarios del mundo y a las grandes capitales, que a veces constituyen un único lugar, de sus pretensiones de totalidad. Esta totalidad nunca nos ha incluido. ¿La literatura -el texto- no sería la que crearía la visibilidad? ¿Existir es, por tanto, poder ser leído? Pero he aquí el dato esencial: lo invisible no es silente. Esa susurrante lógica del fantasma, esta ontología del espíritu leve, es acaso la posibilidad de una última otra palabra. Una anacrónica invanguardia del siglo XXI que habla de un "lugar" que por haber sido rayado no ha sido descubierto. (cursivas originales, p.129)

El lenguaje de lo decible, que ha alcanzado el nivel de canon, se asume como una totalidad que excluye, el archivo, por el contrario, visibilizado mediante la escritura sería un vasto campo de posibles descubrimientos estéticos. Una isla como Puerto Rico, donde nació el escritor Eduardo Lalo, no es un lugar destacado porque carece de atributos que la hagan merecedora de atenciones mundiales. Ya desde su mismo estatus jurídico-político no es una nación independiente, pero tampoco hay un requerimiento firme por serlo. En Puerto Rico están las marcas de un archivo colonial sobrepuesto a la contemporaneidad que simula constituir un país. Escribe Lalo:

\footnotetext{
${ }^{8}$ Escribe Rao al respecto: "En el contexto de las rápidas alteraciones de la fisonomía urbana que cada vez más está haciendo que distintas ciudades se asemejen en apariencia, la especificidad cultural, marcada por el entorno construido, se ha puesto en entredicho. Si los archivos se asocian con la creación y la difusión de formas concretas a modo de significantes de un pasado ausente, la falta de especificidad cultural marcada por la fisonomía urbana complica el proyecto de imaginar la ciudad como un archivo, al menos a nivel de la forma construida" (Rao, 2008, p.200).
} 
Contrariamente a lo que se podría suponer, la invisibilidad es uno de los grandes condicionantes de la historia hoy, en la era de la globalización, lo sea con mayor encono y maldad. La enorme mayoría de los seres del planeta, sean habitantes de Lagos, Caen o San Juan son seres marcados por el hecho de que su existencia no es visible al no ser consumida como relato o teoría. (p.87)

Los archivos pensados como lenguajes antes que, únicamente, como repositorios de documentos al servicio de la memoria podrían justificar la vinculación de las ciudades con el archivo. Para comprender la invisibilidad debemos antes centrarnos en lo que el régimen discursivo autoriza decir. Una hiperexposición del archivo convierte en invisible lo que hasta un tiempo pudo ser objeto de custodia y admiración. Lalo nos enfrenta a la paradójica función del archivo cuando convierte lo que atesora en espacios para "exploradores de lo sabido" (p.23). Lo real ha sido sustituido por medio del estereotipo, por aquello que de antemano ya se sabe que habrá de ser experimentado al portar la imagen en la memoria. La sorpresa ha desaparecido, por lo tanto el misterio como incentivo para el descubrimiento de nuevas emociones y visiones ha dejado lugar a una emoción prefigurada y que se adquiere casi como un paquete turístico. "Venecia -escribe Lalo- es de los turistas y los venecianos han perdido su ciudad por haberla entregado a aquel que viene, toma fotos, compra máscaras de carnaval o cristal de Murano, come pasta y se va convencido de que ha visitado la ciudad más romántica que haya conocido" (p.19). ${ }^{9}$

Por eso Venecia ha muerto como otras ciudades que testimoniaban en su monumentalidad una historia artística que no ha dejado descendencia. Tales ciudades constituían archivos visuales. Pero no es un mal que ataca solamente a las ciudades sino también a la naturaleza (montañas, mares y topografías célebres). El archivo urbano sufre el desgaste de la sobreexposición, mientras que la naturaleza padece la sobreexplotación. Antonio Benítez Rojo publicó hace unos años un ensayo titulado Los archivos de los pueblos del mar. El texto no trata precisamente de la visibilidad de lo globalizado, sino de sus suburbios. El concepto de archivo ayuda al escritor cubano a descifrar el origen de la destrucción de los ecosistemas del archipiélago. La causa (invisibilizada) de esta catástrofe ha sido el sistema de plantación que trajo el colonialismo pero continuó incluso después de que los países alcanzaran su independencia. ${ }^{10}$

El canon, es decir, el Occidente duro, ha pretendido - escribe Lalo- pensar en piedra, esculturalmente, a la manera de un mausoleo. La ha sido muy difícil vislumbrar la condición efímera de la escritura, de ahí sus énfasis: la historia, lo clásico, el museo, el dogma, la raza, el Estado, la nación, el mundo (que confunde como todo lo anterior, consigo mismo). Por ello, es por lo que no ha podido ver a aquellos que actúan desde lo

\footnotetext{
${ }^{9}$ Para Rao: "Los políticos, urbanistas y promotores inmobiliarios venden a los ciudadanos y a los turistas la «imagen-ciudad» creada por estos actos de conservación, como una fuente de ingresos generados a través del turismo de masas, los festivales, los alquileres, etc. En lugares como Mumbai (Bombay), donde, en la actualidad, se están llevando a cabo transformaciones de gran importancia en un intento de convertirla en una ciudad de «primera categoría internacional», el naciente movimiento de conservación del patrimonio histórico sigue estando dominado por los ciudadanos de la elite social" (Rao, 2008, p.199).

10 "Es el lamentable saldo que dejado el colonialismo, la dependencia económica y el sistema de plantación sobre el mundo insular de por sí ya afectado geográficamente por huracanes, inundaciones costeras [...] A continuación, con objeto de representar el archipiélago, tomaré el caso de Cuba. Fue allí donde la plantación de caña de azúcar causó más estragos en el medio ambiente y en la biodiversidad: fue allí donde la monoproducción y la tecnología extranjera, la indiferencia oficial y el oportunismo económico ganaron el primer combate contra la naturaleza" (Benítez Rojo, 2010, p.23).
} 
que consideraría una ausencia de tradición; esos que piensan desde el libro con reproducciones mecánicas y no desde los originales. Y, ésos, también, son Occidente. (p.156)

Si los archivos eran lo que discursivamente no llegaba a decirse, la hipervisibilidad de la globalización ha hecho de los lugares con interés histórico-cultural un mapa elemental de esparcimiento y constatación. Los peligros de desaparición de la ciudad histórica, por lo tanto el archivo que ello conlleva, no serán por el deterioro del tiempo sino por "fagocitarse como copia de sí misma", en palabras de Lalo (p.31). Lalo llama entonces a redireccionar la atención hacia los países o ciudades invisibles. El archivo no es indestructible, el arte ha llevado a cabo usos estratégicos del archivo para deshilvanar aquello que aparecía como intocable o inmodificable. Todo ha sido productivo: de las ruinas y los fragmentos a las huellas. Es así como se alcanza a distinguir la marca colonial que ha sido trazada en la cultura. Asimismo los países invisibles se tornan un lugar de "privilegio", si así puede llamarse, para la expresión artística.

En el plano de la producción cultural, el haber llegado "tarde al banquete de occidente" según la famosa frase de Alfonso Reyes, ofrece algunas ventajas como la indicada por Lalo. Si en Reyes la ventaja con la que corría la cultura occidental respecto de la de América Latina era medida de acuerdo con siglos de diferencia productiva, en Lalo el banquete en el que el continente americano comenzó a participar a destiempo y en posición subalterna debe enfrentarse con cinismo y aprovechar los vacíos que deja el occidente canonizante. El concepto de occidente se compone de un conjunto de libros que formaron un canon pero hoy ni los estados ni las iglesias occidentales controlan a los lectores de las bibliotecas del mundo, razona Lalo (p.181). Los países invisibles devienen miradores desde donde pensar es una acción cínica, ya que occidente como interlocutor teórico no está en condiciones de comprender que tanto el "mundo" como la "tradición" es un límite para del diálogo. Para occidente mundo y tradición son lo que "asume como una realidad dada y propia", asevera Lalo. La ceguera de occidente crea nuevos espacios de exploración de validez universal (p.126). En los nuevos espacios de exploración devenidos de la invisibilidad, la escritura es apócrifa, es decir oculta, invisibilizada por otra que se canoniza. Pero extrañamente para Lalo la escritura apócrifa es la otra cara de occidente, al menos como una posibilidad de cuestionar las políticas del "canon" (p.182). En tal sentido, una "república mundial de las letras" será irrealizable mientras que el margen no sea considerado un campo de producción excéntrico. Algo que está en dudas ante la incapacidad de que los centros puedan "verse fuera de sí", "desde su ex-centricidad" (p.182).

La particularidad de los archivos en los países invisibles afecta también los dominios de la historia en el sentido de cómo se percibe el sujeto en ella. Un archivo no merece ser el recuento de invasiones (en el caso de Puerto Rico, las invasiones de España, Holanda, Inglaterra y Estados Unidos) ¿El único archivo posible de un país invisible, se pregunta Lalo, es el que registra como grandes momentos de la historia el arribo violento y conquistador de otros? La historia de un país invisible es "el recuento de lo que le hicieron", y de lo que "no pudo hacer" (p.165). El país invisible demanda entonces un archivo alternativo que recupere no las grandes efemérides sino un paso del tiempo y acciones que constituyen otros materiales para elaborar un nuevo relato y pensamiento. Habría así otra historia.

Sabemos que el archivo no es solo una noción sino una materialidad compuesta de diversos elementos (soportes legibles, principalmente) que son reunidos en repositorios determinados. También pudimos ver que el archivo va más allá de esta materialidad y se convierte en un "arsenal de autoridad" que le brinda los apoyos necesarios principalmente al 
Estado para su consolidación como tal. Como autoridad (no debe de olvidarse que en su etimología está la acepción mandato ${ }^{11}$ ), el archivo además es una fuente de legitimidad de poderes sectoriales o de clase. Con todo, hemos hecho uso de un sentido metafórico del archivo que nos permitiera conectar lo verbal con lo no lo verbal, es decir, lo discursivo con lo no discursivo. El uso metafórico del archivo ha ido en la dirección de lo que se conoce como dispositivo. Esta orientación con una fuerte base foucaultiana facilitó percibir las relaciones entre ver, saber y poder. Estas tres acciones no se destacan precisamente por dar forma o cuerpo a cosas. Se trata de complejas redes de conexión que recorren una "formación histórica". En palabras de Deleuze, hay probabilidades de definir una nueva formación histórica cuando hay un agenciamiento entre lo visible y lo enunciable. Dicho de otro modo, se produce una combinación de las visibilidades y los enunciados. "La coherencia de una época- escribe Deleuze- está constituida por el hecho de que sus visibilidades [...] son combinables con sus enunciados, en virtud de sus formas propias" (Deleuze, 2013, p.33). Para el filósofo esta operación es contundente, ya que distingue una formación de otra. Las visibilidades y las enunciabilidades no son conmutables de una formación a otra. Desde este andarivel fue posible detenerse en la obra de Eduardo Lalo, Los países invisibles. En la obra del escritor portorriqueño el archivo no concita el interés principal, por el contrario, Lalo le presta más atención al canon de occidente. Sin embargo, el canon de occidente trabaja como una máquina invisilizadora de los países que han quedado fuera de su horizonte de "visión". Lalo descubre que hay países autocentrados y otros que son excéntricos. Esta dualidad significa que existe una autoridad que la facilita o incentiva. En la formación histórica que nos presenta Eduardo Lalo, lo visible y lo enunciable están escindidos. En algunos casos por lo que ya se ha dicho, es decir por el acto no ver pero en otros casos, por una sobreexposición que tiene idénticos efectos: borrar lo que está en la visión. La recuperación del archivo que denote otros sentidos a la cultura de un país no consiste en una tarea de perforación de una superficie, buscando en las profundidades, sino en el recorrido extensivo de la superficie dándole forma verbal a lo que ya estaba pero había dejado de ser visto. A pesar que entre el ver y el decir hay una no-relación (Deleuze, 2013, p.31), Lalo a sabiendas de ello propone convertir los países invisibles en lugares donde la escritura sea soberana. Ello significa que la invisibilidad de una cultura en lugar de ser una desventaja podría ser el comienzo de una nueva relación entre lo que se dice y lo que se ve.

\section{Referencias Bibliografícas}

Agamben, G. (2016). Lo que queda de Auschwitz. El archivo y el testigo. Trad. Antonio Gimeno Cuspinera. Valencia: Pre-textos.

Albizúrez Gil, M. (2013). El material humano de Rodrigo Rey Rosa. El archivo como disputa, Centroamericana, 5-30.

Benítez Rojo, A. (2010). Archivo de los pueblos del mar, San Juan: Ediciones Callejón. Catanzaro, G. (2011). La nación entre naturaleza e historia. Buenos Aires: Siglo XXI.

${ }^{11}$ Derrida remite el significado etimológico de archivo hasta los “arcontes, los que mandaban" (Derrida, 1997, p.10). 
Coto-Rivel, S. (2015). Ficción de archivos: memoria y heterotopía en El material humano de Rodrigo Rey Istmo. Revista virtual de estudios literarios y culturales centroamericanos, ISTMO, recuperado de https://hal.archives-ouvertes.fr/hal-01709346/document.

Deleuze, G. (2013). El saber. Curso sobre Foucault. 1ra ed. Buenos Aires: Cactus.

Derrida, J. (1997). Mal de archivo. Una impresión freudiana. Madrid: Editorial Trotta.

Foucault, M. (1985). Arqueología del saber. Trad. Aurelio Garzón del Camino. México: Siglo XXI.

Fuentes, C. (1985). Gringo viejo. México: Fondo de Cultura Económica.

Gizzo, L. del (2018). El Canon frente al archivo. Avatares metodológicos de una relación complementaria. Chuy. Revista de estudios literarios latinoamericanos, Número 5, diciembre 2018, 45-69.

Hernández-Navarro, M. (2009). Archivo escotómico de la modernidad [pequeños pasos para una cartografía de la visión]. Centro de Estudios visuales de Chile. Recuperado de http://www.centroestudiosvisuales.cl

Lalo, E. (2014). Los países invisibles. Buenos Aires: Corregidor.

Montes, L. (2008). Una Revisión De Las Periodizaciones Archivísticas De La Edad Moderna Española. Documenta \& Instrumenta, 6, 119-145.

González Echavarría, R. (2000). Mito y archivo. Una teoría de la narrativa latinoamericana. México: Fondo de Cultura Económica.

Ocampo López, J. (2006) Mitos, creencias en los procesos de cambio en América Latina. América Latina en sus ideas. Coord. e introd. de Leopoldo Zea. 4ta edición. México: Siglo XXI.

Ortiz Wallner, A. (2018). Orientalismos, canon y archivo en la ciudad. Iberoromania, 87, 96-107.

Oto, A. de (2011). Aimé Césaire y Frantz Fanon. Variaciones sobre el archivo colonial/descolonial. Tabula Rasa, núm. 15, julio-diciembre, pp. 149-169. Recuperado de https://www.revistatabularasa.org/numero15/

Peiró Graner, M. (2001). El archivo como espacio del saber El edificio de archivo. Boletín Millares Cado, 245-279.

Perilli, C. (2013). Metáforas del archivo en la narrativa latinoamericana. Revista Pilquen, Año XV, Vol. 16 Suplemento Especial, 1-10.

Rama, A. (2004). La ciudad letrada. Pról. Carlos Monsiváis. Santiago de Chile: Tajamar Editores.

Rao, V. (2008). Transformaciones urbanas contemporáneas y la posibilidad de la política. Educación y vida urbana. Madrid: Santillana.

Rey Rosa, R. (2009). El material humano. Barcelona: Anagrama.

Ricoeur, P. (2006). Tiempo y narración III. 4ta ed. México: Siglo XXI.

Rufer, M. (2016). El archivo: de la metáfora extractiva a la ruptura poscolonial. En Frida G., Rufer, M. coords. (In)disciplinar la Investigación: Archivo, trabajo de campo y escritura. México: Siglo XXI.

Salinas C., M. (2019). Dilemas e invenciones del tiempo lineal burgués en Chile. siglos XIXXXI. Tabula Rasa, 30, 47-66.

Sciascia, L. (1985). El archivo de Egipto. Barcelona: Seix Barral. 